\title{
Article \\ Cobalt Oxide on a Nanoporous TUD-1 Catalyst for Methylene Blue Dye Interaction DFT Studies and Degradation
}

\author{
Muthusamy Poomalai Pachamuthu ${ }^{1, *}$, Sambath Baskaran ${ }^{2, *}$ (D) Chandrakumar Manivannan ${ }^{1}$, \\ Somasundaram Chandra Kishore ${ }^{3, *}$, Stefano Bellucci ${ }^{4}\left(\mathbb{D}\right.$ and Ramasamy Boopathy ${ }^{5}$ \\ 1 Department of Chemistry, Sensors Lab, Bannari Amman Institute of Technology, \\ Sathyamangalam 638401, India; cmanivannan89@gmail.com \\ 2 Department of Chemistry, Southern University of Science and Technology, Shenzhen 518055, China \\ 3 Department of Biomedical Engineering, Saveetha Institute of Medical and Technical Sciences (SIMTS), \\ Saveetha School of Engineering, Saveetha University, Chennai 602105, India \\ 4 INFN-Laboratori Nazionali di Frascati, 00044 Frascati, Italy; stefano.bellucci@lnf.infn.it \\ 5 Environment \& Sustainability Department, CSIR-Institute of Minerals and Materials Technology, \\ Bhubaneswar 751013, India; boopathy@immt.res.in \\ * Correspondence: pachachem@gmail.com (M.P.P.); baskarsambath@gmail.com (S.B.); \\ schandrakishore30@gmail.com (S.C.K.)
}

Citation: Pachamuthu, M.P.; Baskaran, S.; Manivannan, C.; Kishore, S.C.; Bellucci, S.; Boopathy, R. Cobalt Oxide on a Nanoporous TUD-1 Catalyst for Methylene Blue Dye Interaction DFT Studies and Degradation. Symmetry 2021, 13, 1754. https://doi.org/10.3390/sym13091754

Academic Editor: Laura Bulgariu

Received: 28 August 2021

Accepted: 16 September 2021

Published: 20 September 2021

Publisher's Note: MDPI stays neutral with regard to jurisdictional claims in published maps and institutional affiliations.

Copyright: (C) 2021 by the authors. Licensee MDPI, Basel, Switzerland. This article is an open access article distributed under the terms and conditions of the Creative Commons Attribution (CC BY) license (https:// creativecommons.org/licenses/by/ $4.0 /)$.

\begin{abstract}
Fenton and Fenton-like advanced oxidation processes (AOP) have been substantially utilized in wastewater treatment for the removal of organic contaminants. The present investigation explores the catalytic activity of cobalt dispersed over nanoporous silicate material (CoO/TUD-1), TUD-1, for the Fenton-type degradation of methylene blue (MB) dye present in wastewater, with hydrogen peroxide $\left(\mathrm{H}_{2} \mathrm{O}_{2}\right)$ as an oxidant. The catalyst, which was prepared using the hydrothermal method, was characterized using analytical and spectroscopic techniques, such as X-ray diffraction (XRD), $\mathrm{N}_{2}$ adsorption-desorption isotherms, UV-visible diffuse reflectance (DR), scanning electron microscope (SEM), transmission electron microscopy (TEM) and Fourier transform infrared (FTIR). The results indicated that the CoO/TUD-1 possessed three-dimensional structures with a high surface area and a pore diameter capable of the uniform dispersion of cobalt species. Density functional theory (DFT) simulations were performed to study the most stable tetra coordinate adsorption configuration of a single $\mathrm{Co}$ atom on amorphous $\mathrm{SiO}_{2}$. To understand the geometric and electronic structure of this configuration, electron density differences, Bader charge, and partial density of states were examined. The results obtained from the DFT calculations confirmed the occurrence of electron transfer from the $\mathrm{Co}$ atom to the amorphous $\mathrm{SiO}_{2}$. The calculated adsorption energy was found to be $-1.58 \mathrm{eV}$, which indicated that the MB dye was strongly adsorbed by parallel configuration mode and degraded more easily. Further, the addition of a $0.1 \mathrm{~g} / \mathrm{L}$ dose of the prepared CoO /TUD degraded the MB dye effectively ( 95\%) within 240 min of contact. Thus, CoO/TUD-1 is a potential material for the removal of organic contaminants and the degradation of dyes in wastewater treatment.
\end{abstract}

Keywords: mesoporous; TUD-1; methyl blue degradation; density functional theory

\section{Introduction}

Over the past decade, water treatment and purification have been a significant are of concern in the fields of chemical and environmental science [1-3]. With the rapid growth of the textile and dye industries, more and more essential commercial dyes and several other synthetic toxic chemicals are dumped through various means into water bodies. Methylene blue (MB), a heterocyclic aromatic chemical compound with the molecular formula $\mathrm{C}_{16} \mathrm{H}_{18} \mathrm{ClN}_{3} \mathrm{~S}$ is one of the most commonly used thiazine dyes in the textile, paper, fabrics, food and cosmetics industries [4,5]. This dye is anti-biodegradable and incompatible with bases, reducing and strong oxidizing agents. In case of a chemical reaction, this dye compound completely removes the dissolved oxygen present in water bodies and also 
discharges various toxic compounds that are hazardous to ecosystems [5]. In humans and animals it can cause severe damage to eyes, unpleasant respiration after inhalation, nausea, diarrhea, excessive sweating, mental discomfort and methemoglobinemia [6].

There are various methods available for the removal of $\mathrm{MB}$, such as photocatalytic degradation [7], biological degradation [8], advanced chemical oxidation [9], nano filtration [10] and ultra-filtration [11]. Advanced oxidation processes (AOPs) are an important method for wastewater treatment $[12,13]$. Fenton or photo-Fenton reactions are known to be a promising class of AOP. These reactions use an iron-based catalyst that can react with $\mathrm{H}_{2} \mathrm{O}_{2}$ (oxidizing agent) to release hydroxide radicals $(\bullet \mathrm{OH})$ that result in the degradation of various organic contaminants into non-toxic by-products [14-19]. The classical homogeneous Fenton reagent comprising $\mathrm{Fe}^{2+}$ and $\mathrm{H}_{2} \mathrm{O}_{2}$ has been shown to be of useful degradation ability and general scope, although the need for acidic conditions to avoid the hydrolysis of ferrous and ferric ions and the removal of iron ion-containing sludge make this process costly and unsustainable. Heterogeneous methods of Fenton employing solid catalysts, such as iron oxide nanoparticles, were explored as a potential solution [20]. However, these technologies focused on nanoparticles and demonstrated with many pitfalls, such as high metal ion leaching, low catalytic performance, agglomeration of nanoparticles, and high recovery costs.

The heterogenization of the homogeneous catalysts offers a variety of advantages as it involves simplicity of isolation and reusability of the catalyst. Several heterogeneous catalysts were widely studied for cobalt-based catalytic systems, such as $\mathrm{Co}_{3} \mathrm{O}_{4}$ and $\mathrm{CoFeO}_{4}$ nanoparticles, which suffered leaching problems [21,22]. Various efforts were devoted to immobilize the cobalt species on several supports, such as graphene oxide, activated carbon, carbon nanotube, titanium oxide and magnesium oxide [23-25]. Nonetheless, such catalytic supports suffered from high-cost materials synthesis, and their low catalytic activity performance, due to their lower porosity, hindered the development of various chemical reactions. In general, methylene blue (MB) is low-biodegradable in nature; it was therefore essential to have catalytic material with a high degradation capability. TUD-1 is a three-dimensional mesoporous silica material with high thermal stability and a sponge-like structure with tunable pores, which create a significantly large surface area [26-30].

Recently, we reported an efficient, simple, one-pot hydrothermal synthesis method of cobalt-incorporated amorphous disordered mesoporous silica, TUD-1 [29]. These catalysts proved to be catalytically active and better candidates compared to other ordered mesoporous materials. The presence of Co-atrane and silatrane complexes during the synthesis of TUD-1 enables a broad dispersion of Co species within or at the surface of the silica network. These materials have the benefit of incorporating higher concentrations of active metal ion species with relatively similar distributions of pore size, thus evading the leaching effect. The redox, acid base, physicochemistry, and behavior of nanostructured catalysts, and therefore their interaction with dye molecules, are all tuned by symmetry in terms of particle size and shape, yielding unique catalytic activity. The present investigation reports on the economical synthesis and characterization of cobalt-oxide-impregnated TUD-1 material suitable for the adsorption, followed by degradation, of MB. In addition, DFT studies were also carried out to study the most stable adsorption configuration of a single $\mathrm{Co}$ atom on amorphous $\mathrm{SiO}_{2}$. The geometric and electronic structure of the configuration were studied based on electron density differences, Bader charge and partial density of states. The binding energy of $\mathrm{MB}$ at various possible configurations was also investigated. The catalytic activity of CoO/TUD-1 was studied through the degradation of MB, thus exploiting its potential application for the removal of organic pollutants.

\section{Materials and Methods}

\subsection{Materials}

Tetraethyl orthosilicate (98\%, TEOS, ACROS, Carlsbad, CA, USA), triethanolamine ( $97 \%$, TEA, ACROS, Carlsbad, CA, USA), tetraethyl ammonium hydroxide $(35 \%$, TEAOH, 
Aldrich, St. Louis, MO, USA), cobalt nitrate $\left(\mathrm{Co}\left(\mathrm{NO}_{3}\right)_{2} \cdot 3 \mathrm{H}_{2} \mathrm{O}\right.$, Merck, Germany) and double distilled water.

\subsection{Catalyst Synthesis}

As reported in our previous works, a mesoporous TUD-1 sample was prepared by aging, drying, and calcining a homogeneous synthesis mixture comprising a tetraethyl orthosilicate (TEOS) as a silicon alkoxide precursor and triethanolamine (TEA) [29]. A mixture of TEA (97\%, ACROS, Carlsbad, CA, USA) and $\mathrm{H}_{2} \mathrm{O}$ was added dropwise into TEOS (98\%, ACROS, Carlsbad, CA, USA) under stirring. Lastly, tetraethyl ammonium hydroxide (TEAOH, 35\%, Aldrich, St. Louis, MO, USA) was applied dropwise. A smooth and pale yellow solution was obtained after stirring for $2 \mathrm{~h}$, with a molar ratio composition of $1 \mathrm{SiO}_{2}: 0.3 \mathrm{TEAOH}: 1 \mathrm{TEA}: 11 \mathrm{H}_{2} \mathrm{O}$. The mixture was aged for $24 \mathrm{~h}$ at room temperature, dried for $24 \mathrm{~h}$ at $373 \mathrm{~K}$, hydrothermally treated for $4 \mathrm{~h}$ in a Teflon-lined stainless steel autoclave, and then calcined for $10 \mathrm{~h}$ at $873 \mathrm{~K} .10 \mathrm{wt} . \%$ of cobalt oxide supported on SiTUD-1 was prepared by the conventional impregnation method using cobalt salt solution. Finally, the obtained material was named as CoO/TUD-1.

\subsection{Characterization}

The X-ray diffraction (XRD) measurement was carried out on a Rigaku, Japan diffractometer with a $\mathrm{Cu} \mathrm{K} \alpha(\lambda=1.5418 \AA)$ radiation source in the $2 \theta$ range $10-80^{\circ}$. The BET isotherm was evaluated from nitrogen sorption carried out at $-196{ }^{\circ} \mathrm{C}$ using a Micromeritics ASAP 2020, USA porosimeter. The transmission electron microscopy (TEM) was performed on a FEI Tecnai G2, USA fitted with a CCD camera. The FTIR spectra of KBr-diluted pellets from the sample were recorded on a FTIR-Bruker (Tensor), Germany instrument measured in the range of 4000 to $400 \mathrm{~cm}^{-1}$. The UV-visible diffuse reflectance spectra of the samples were recorded on a thermo scientific, (Evolution 600) UK spectrometer.

\subsection{Computational Methods}

All spin polarization calculations were conducted by density functional theory (DFT) level using the Vienna ab initio simulation package (VASP) [30-32]. The projector-augmented wave (PAW) method was used to define the interactions between the ion cores and valence electrons and the generalized gradient approximation (GGA)-Perdew-Burke-Ernzerhof (PBE) exchange-correlation function was implemented [33,34]. The plane wave kinetic energy cut off of fixed to be $450 \mathrm{eV}$. The Brillouin zone in the reciprocal space was sampled by the $1 \times 1 \times 1 \Gamma$ point. All the ions were allowed to relax until the maximum force was less than $0.03 \mathrm{eV} / \AA$ A. Van der Waals interactions were applied using the DFT-D3 approach, as employed in VASP [35]. The electron charge transfer was calculated using grid-based Bader analysis [36,37].

\subsection{Fenton Oxidation Reaction}

The Fenton oxidation of MB was carried out in a $1000 \mathrm{~mL}$ polypropylene bottle fitted with a magnetic stirrer. The catalytic activity of the catalyst was evaluated according to the degradation of $\mathrm{MB}(100 \mathrm{ppm})$ by the batch process under a $100 \mathrm{rpm}$ stirring speed at room temperature. A total of $100 \mathrm{~mL}$ of methylene blue solution (100 ppm) and $6.4 \mathrm{mmol} / \mathrm{L}$ of $\mathrm{H}_{2} \mathrm{O}_{2}(30 \%)$ were added to the bottle. To initiate the degradation, known MB solution was mixed with the $\mathrm{H}_{2} \mathrm{O}_{2}$ oxidant and stirred. Finally, $0.1 \mathrm{~g} / \mathrm{L}$ of the preheated catalyst $\mathrm{CoO} / \mathrm{TUD}-1$ were added and the reaction flask was kept in the stirrer at room temperature. The samples were withdrawn periodically and analyzed using the UV-visible spectrophotometer. The conversion and product selectivity were calculated based on the peak intensity and concentration variations. The MB degradation was calculated from the following expression:

$$
\text { Percentage degradation }=\left[\mathrm{C}_{\mathrm{o}}-\mathrm{C}_{\mathrm{t}} / \mathrm{Co}\right] * 100
$$


where $C_{o}=$ Initial concentration of the dye solution and $C_{t}=$ Concentration remaining after irradiation at time $t$.

\section{Results and Discussion}

\subsection{Characterization of CoO/TUD-1 Material}

The amorphous nature of the prepared catalyst was examined using XRD studies. Figure 1 depicts the wide angle XRD diffraction pattern of calcined CoO/TUD-1. The presence of a broad peak in the range of $10-40^{\circ}$ indicates the amorphous nature of silica $[38,39]$. No peaks corresponding to cobalt oxide species are visible; this might be due to the fact that they were incorporated into the silica framework, or they may have been distributed homogeneously through mesoporous TUD-1 channels [29]. The mesoporosity of the catalyst, the specific surface area and volume of the pores and the characteristics that enabled bonding between the active sites and the guest molecules on the surface of the pores and across the bulk of the material were examined by Brunauer-Emmett-Teller (BET). Figure 2a illustrates the sorption isotherm of CoO/TUD-1, representing a type-IV adsorption according to the IUPAC classification, indicating the mesoporous structure of $\mathrm{CoO} / \mathrm{TUD}-1$ [40]. Further, at a relative pressure range of 0.7 to $0.9 \mathrm{P} / \mathrm{Po}$, a large intake of nitrogen was well observed. This is due to the capillary condensation that occurs in mesoporous structure [26]. The pore sizes distributions were found to be narrow, with calculated values in the range of $6.8 \mathrm{~nm}$. Based on the Barrett-Joyner-Halenda (BJH) method, the surface area was estimated to be $420 \mathrm{~m}^{2} / \mathrm{g}$.

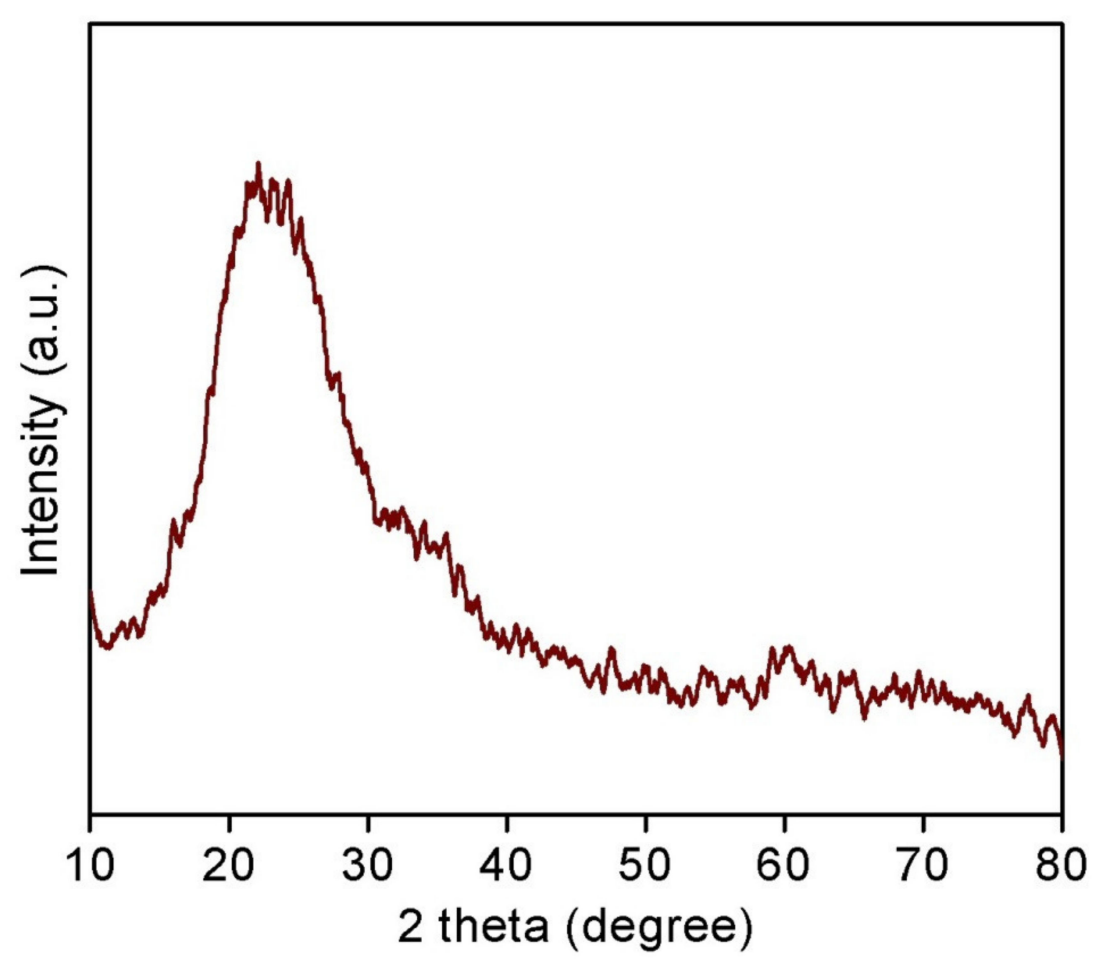

Figure 1. Wide angle powder XRD patterns of CoO/TUD-1. 

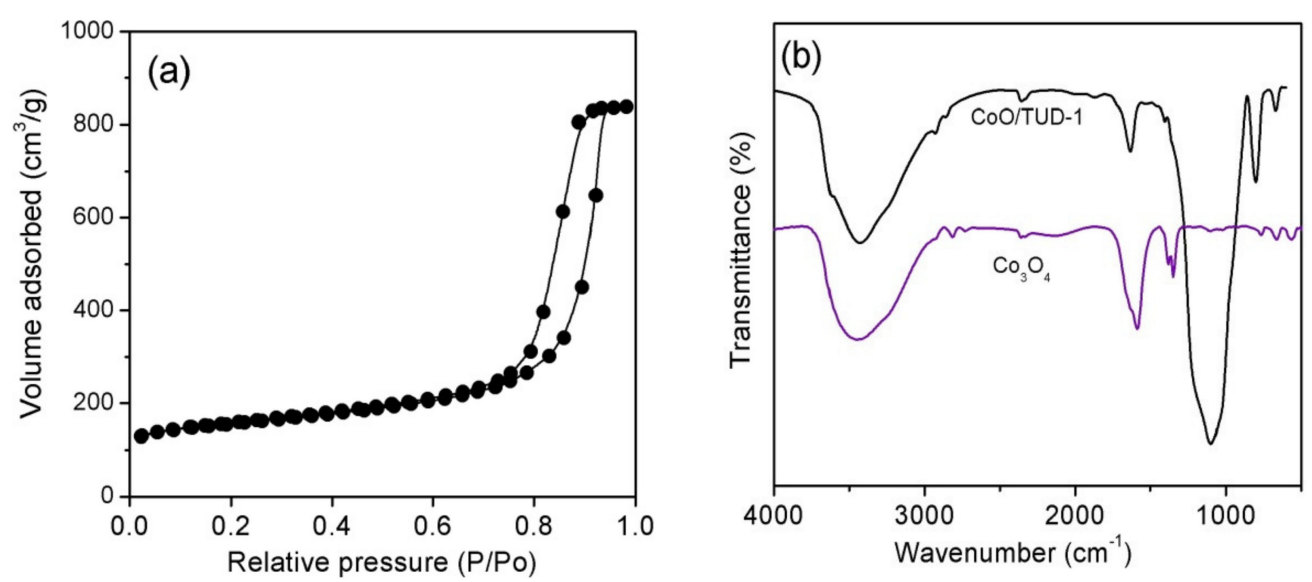

Figure 2. (a) Nitrogen adsorption-desorption isotherm of CoO/TUD-1 and (b) FTIR spectrum of calcined $\mathrm{CoO} / \mathrm{TUD}-1$ and pure $\mathrm{Co}_{3} \mathrm{O}_{4}$.

The chemical functional groups present on the surface of the calcined CoO/TUD-1 and pure $\mathrm{Co}_{3} \mathrm{O}_{4}$ were studied using FT-IR, as shown in Figure 2b. The presence of a broad band around $3460 \mathrm{~cm}^{-1}$ was attributed to the $\mathrm{O}-\mathrm{H}$ stretching vibration of the water molecules adsorbed over the catalyst's system or its surface silanol groups ( $\mathrm{i}-\mathrm{O}-\mathrm{H})$. This was reconfirmed through the corresponding bending vibration mode formed at $1640 \mathrm{~cm}^{-1}$. The asymmetrical and symmetrical stretching vibrations of the $\mathrm{Si}-\mathrm{O}-\mathrm{Si}$ bond present in the TUD-1 were confirmed through the intense vibration bands detected at 1238, 1087 and $804 \mathrm{~cm}^{-1}$. Further, these bands are absent in pure $\mathrm{Co}_{3} \mathrm{O}_{4}$. The formation of an absorption band at $962 \mathrm{~cm}^{-1}$ was ascribed to the stretching vibration of the $\mathrm{Si}-\mathrm{O}$ units bound to $\mathrm{Co}$ or $\mathrm{H}[29,41]$. Notably, the smaller peaks noticed at 578 and $669 \mathrm{~cm}^{-1}$ corresponded to Co-oxygen vibrational modes.

The UV-visible DR spectra of the CoO/TUD- 1 and the $\mathrm{Co}_{3} \mathrm{O}_{4}$ are illustrated in Figure 3. The peak noticed at $520 \mathrm{~nm}$ was assigned to the framework connected to the Co species, which is common for Co-modified mesoporous materials. Notably, compared with the $\mathrm{Co}_{3} \mathrm{O}_{4}$ absorbance bands, a broad absorbance band at a $356 \mathrm{~nm}$ wavelength region was detected in the CoO/TUD-1 sample. A shift in wavelength towards the lower region was associated with the non-framework octahedral coordinated $\mathrm{Co}^{3+}$ in the $\mathrm{Co}_{3} \mathrm{O}_{4}$ species [29]. From this observation, it was confirmed that cobalt was coordinated with silica. The bonding of $\mathrm{Si}, \mathrm{O}$ and cobalt oxide in the CoO/TUD-1 catalyst is presented in Scheme 1.

To capture the morphology of the catalyst, SEM and TEM studies were performed. The SEM images, shown in Figure $4 \mathrm{a}-\mathrm{c}$, revealed the foam- or stone-like morphology of the $5 \mathrm{wt}$.\% of cobalt (confirmed from Energy Dispersive X-ray Analysis (EDAX)) doped catalyst. Further, the TEM images shown in Figure 4d,e clearly depict a 3D sponge-like structure, which confirm that CoO/TUD-1 is a mesoporous material. The dark spots in the catalyst indicate the silica and cobalt species with uniform dispersion over the surface of silicon framework. This confirms the anchoring of the cobalt species over TUD-1 that facilitated the efficiency of the catalytic reaction and its stability. It is clear from the image that the presence of a 3D mesoporous structure in CoO/TUD-1 is an ideal catalytic system for many chemical reactions.

\subsection{Methyl Blue Dye Degradation over CoO/TUD-1 \\ 3.2.1. About the Model}

Tielens et al. proposed and confirmed the slab model of the amorphous silica $\left(\mathrm{SiO}_{2}\right)$ TUD-1's geometry and successfully applied the of grafting various metal and metal oxides on its surface [42-46]. The unit cell parameters of the silica's surface $(a=12.77 \AA, b=17.64 \AA$, $\mathrm{c}=25.17 \AA$ ), consisted of 120 atoms $\left(\mathrm{Si}_{27} \mathrm{O}_{67} \mathrm{H}_{26}\right)$. In this study, the original surface of the silica featured a silanol number of $5.8 \mathrm{OH} \mathrm{nm}^{-2}$ and was partially dehydroxylated to mimic the catalyst calcination conditions [46]. The final dehydroxylated surface of the 
silica model had a silanol density of $3.1 \mathrm{OH} \mathrm{nm}{ }^{-2}\left(\mathrm{Si}_{27} \mathrm{O}_{64} \mathrm{H}_{20}\right)$ [46]. The single cobalt atom embedded onto the silica's surface and the cobalt atom coverage in our modelled surface was around 0.4 atoms $\mathrm{nm}^{-2}$. At the same coverage, the Philips catalyst achieved the highest activity [46].

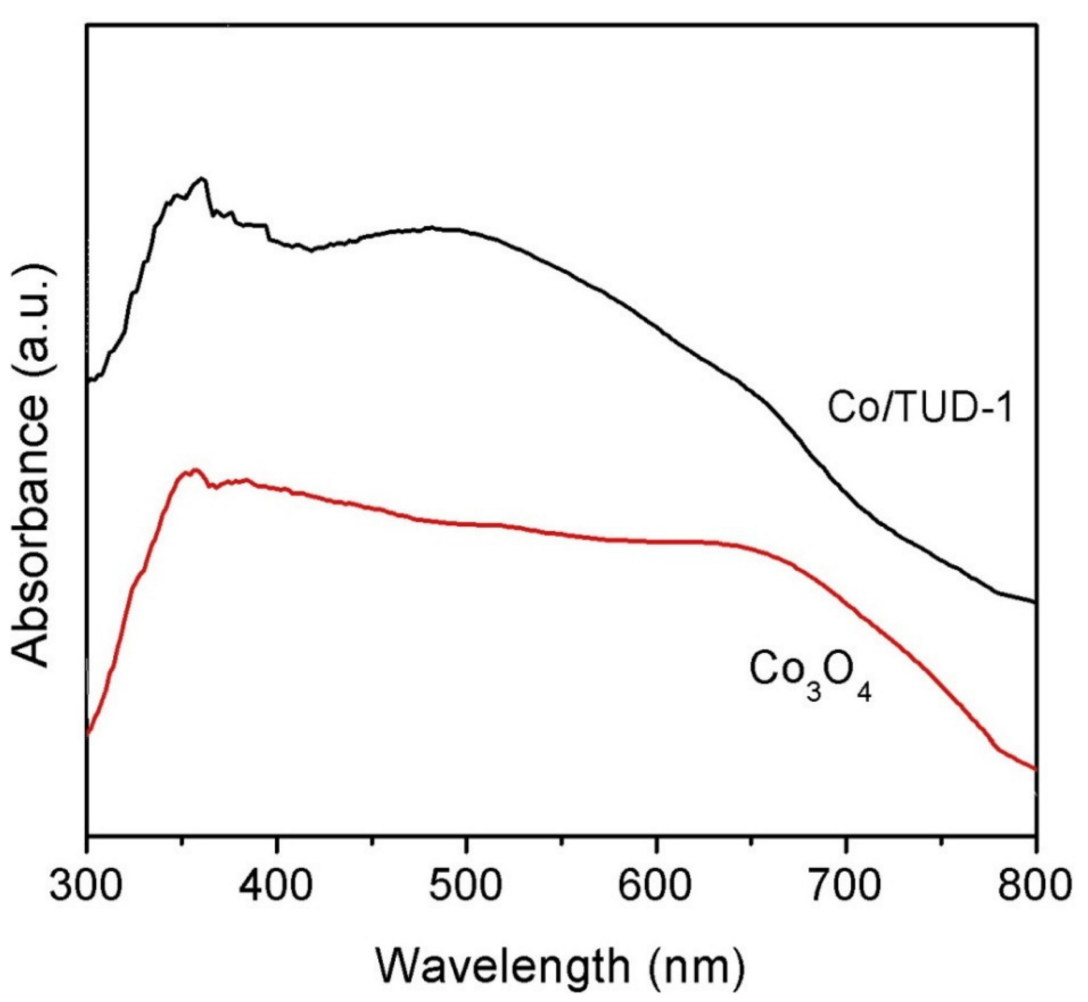

Figure 3. UV-visible diffuse reflectance spectra of $\mathrm{CoO} / \mathrm{TUD}-1$ and pure $\mathrm{Co}_{3} \mathrm{O}_{4}$.

(a)

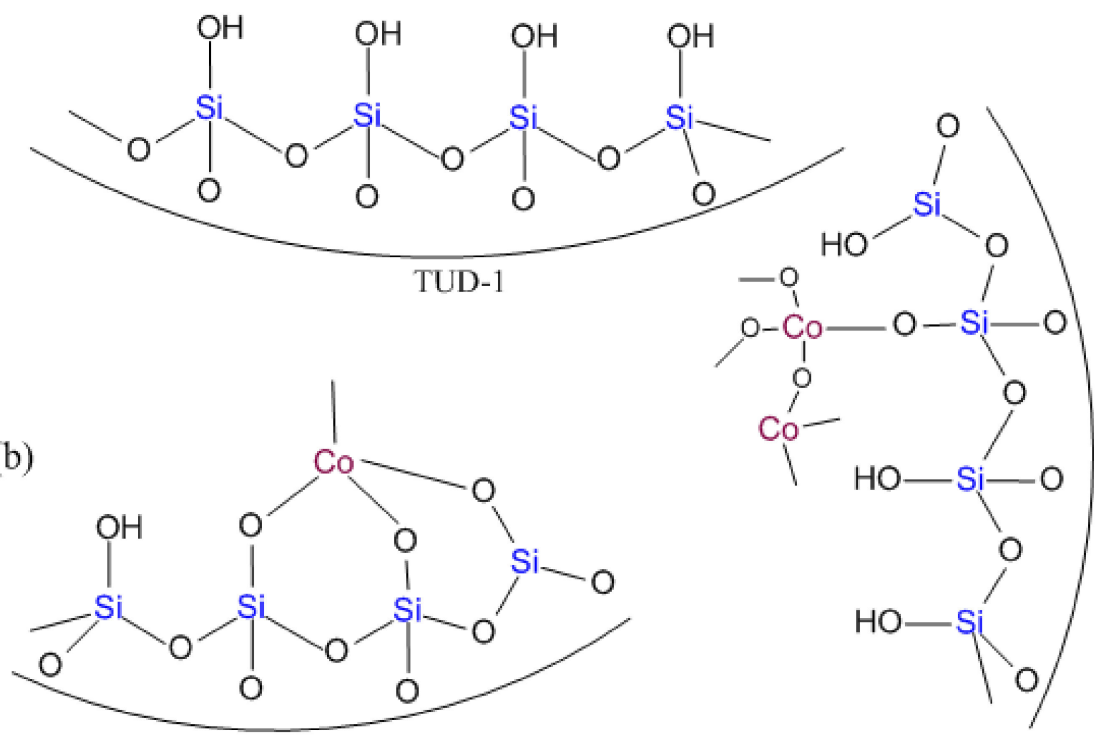

Co/TUD-1

Scheme 1. (a) Proposed structure of TUD-1, (b) proposed structure of possible bonding in CoO/TUD1 catalyst formation. 

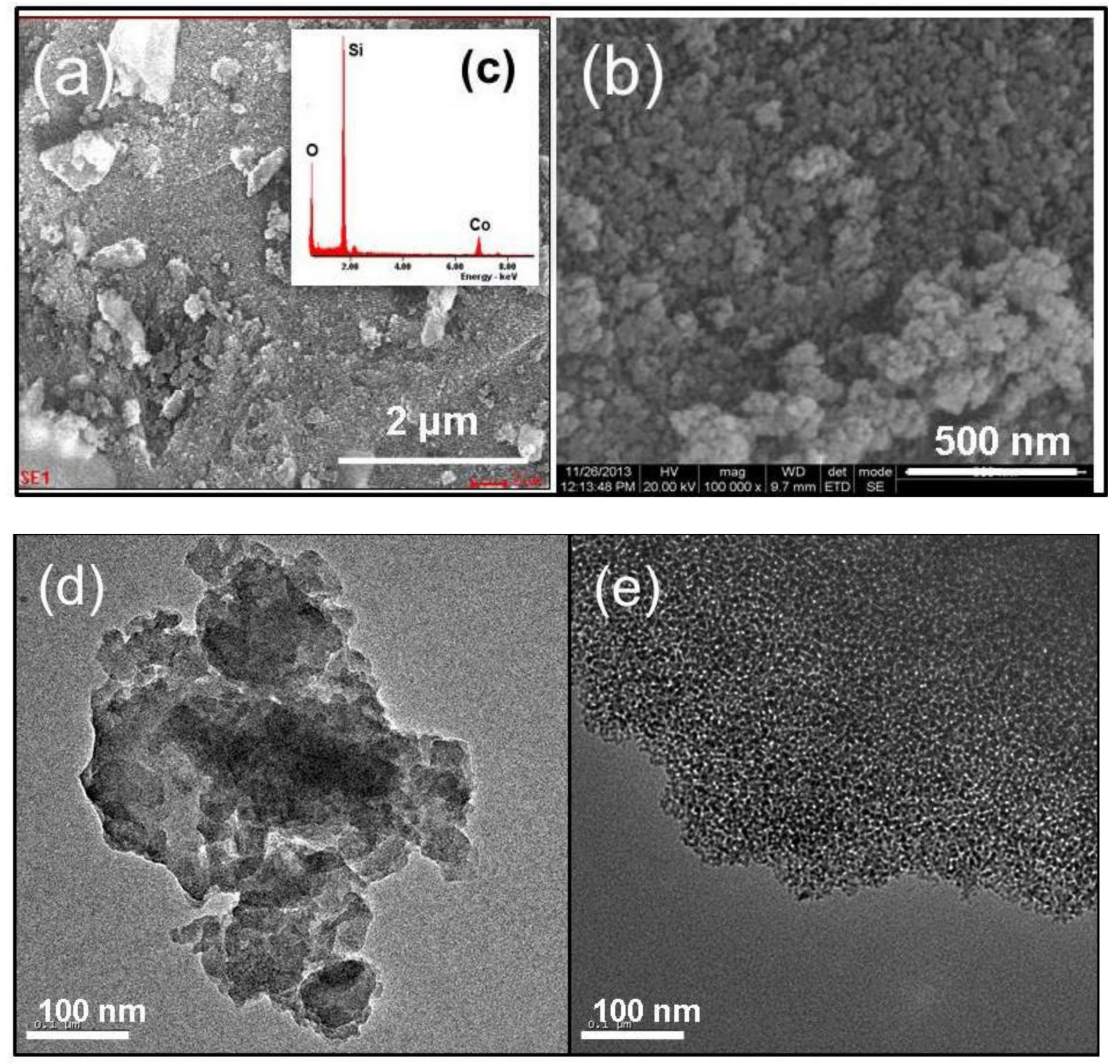

Figure 4. SEM images: (a-c) EDAX; and (d,e) TEM images of CoO/TUD-1.

\subsubsection{Adsorption of Single Co Atom}

DFT calculations were performed to study the most stable tetracoordinate adsorption configuration of the single Co atom on TUD-1. The single Co atom was dispersed on the amorphous $\mathrm{SiO}_{2}$ TUD-1 surface over its oxygen $(\mathrm{O})$ atoms through the dissociation of the corresponding hydrogen $(\mathrm{H})$ atoms to form $\mathrm{Co}-\mathrm{O}-\mathrm{Si}$ bonds. Different kinds of tetracoordinate adsorption configurations were investigated and the corresponding calculated binding energy is shown in Figure S1. The obtained binding energies of the different coordination modes were -2.69 to $-2.80 \mathrm{eV}$, indicating that all the six configurations were energetically stable. In this configuration, A was more stable than the other configurations; the most stable optimized geometry of CoO/TUD-1 (A) and the corresponding geometrical parameters are shown in Figure 5.

To understand the geometric and electronic structure of configuration A, we studied the electron density differences, Bader charge and partial density of states (PDOS). As can be seen from the electron density differences (EDD) plot in Figure 6a, there was a noticeable electron transfer from the $\mathrm{Co}$ atom to the $\mathrm{am}-\mathrm{SiO}_{2}$, and the obtained Bader charge of the Co atom (1.21 le l) was consistent with the experimental oxidation state of cobalt (II). The electron spin density CoO/TUD-1 of 2.89 corresponded to a high spin and three unpaired electrons in cobalt with the $\mathrm{d} 7$ electronic configuration $[47,48]$. To gain a good understanding of the interaction of CoO/TUD-1, the PDOS was performed, and the results are displayed in Figure $6 \mathrm{~b}$. The robust contact between the Co and O of TUD-1 was further established by the formation of overlapped peaks. Furthermore, Co- $3 \mathrm{~d}$ and $2 \pi^{*}$ states of $\mathrm{O}$ were observed near to the Fermi level (EF), suggesting the strong interaction between the $\mathrm{Co}$ and $\mathrm{O}$ atoms.

\subsubsection{Adsorption of Methylene Blue on CoO/TUD-1}

We considered three different possible adsorption configurations, as shown in Figure 7. The calculated adsorption energy $\left(\mathrm{E}_{\mathrm{ad}}\right)$ of the parallel configuration was $-1.58 \mathrm{eV}$, and vertical configurations, such as S-top and S-down, were $-1.29 \mathrm{eV}$ and $-1.12 \mathrm{eV}$ respectively, 
which indicated that methylene blue adsorbed more strongly in the parallel configuration mode and degraded more easily.

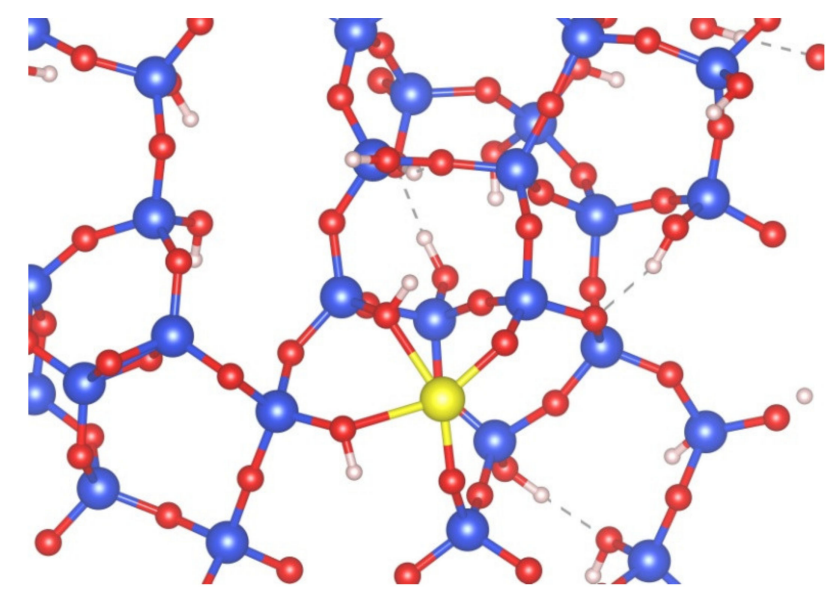

Figure 5. The optimized geometry of CoO/TUD-1. The bond lengths are given in $\AA$. The blue, red and yellow spheres represent $\mathrm{Si}, \mathrm{O}$ and $\mathrm{Co}$, respectively.
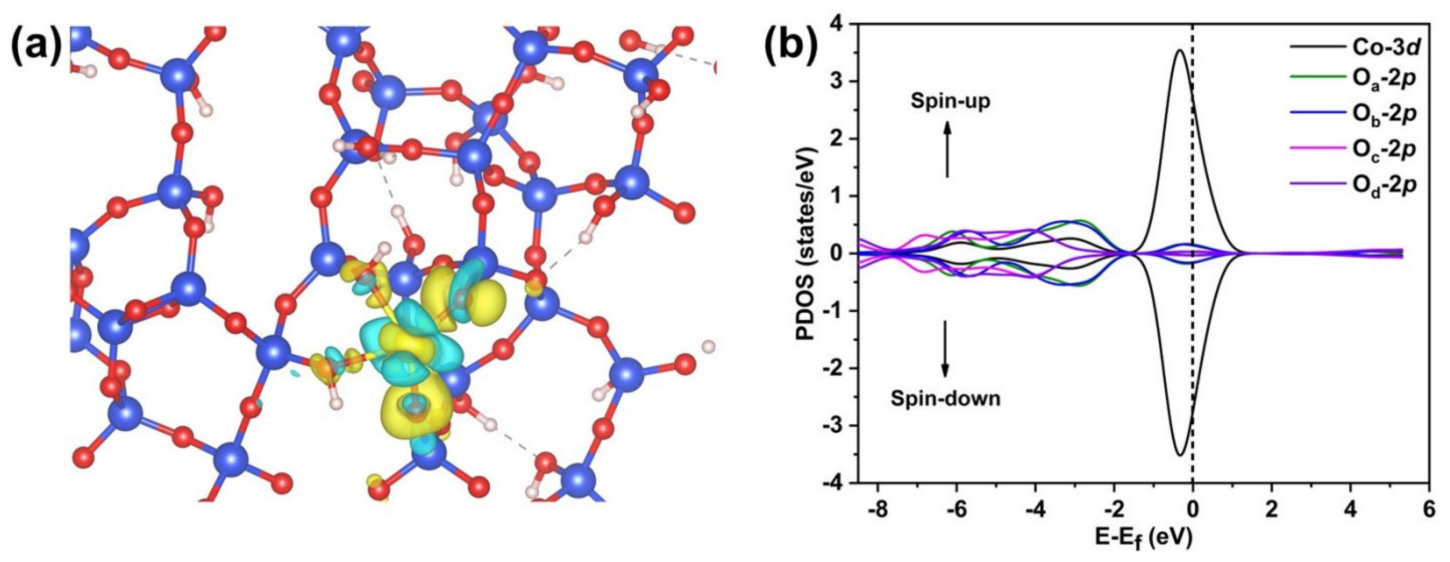

Figure 6. (a) Electron density differences (EDD). For the contour plots, the charge accretion areas are displayed in yellow, while the charge deduction areas are displayed in cyan. (b) The PDOS of Co-3d (black) and O-2p (Oa (green), Ob (blue), Oc (magenta) and Od (purple) states. The Fermi level was set to zero, as shown by the dashed line.

(a)

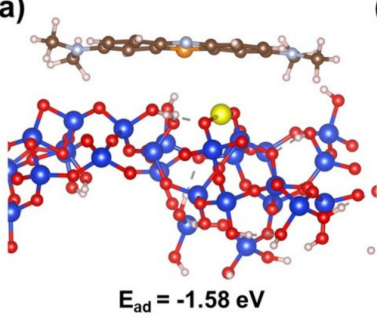

(b)

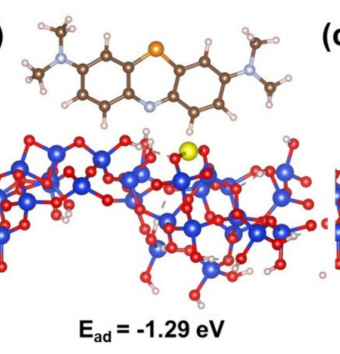

(c)

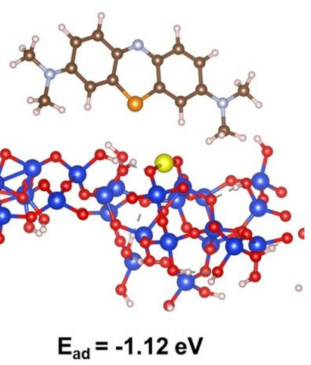

Figure 7. Three different adsorption configurations of methylene blue on TUD-1 surface: (a) Parallel; (b) vertical S-top; and (c) vertical S-down.

\subsubsection{Degradation of Methylene Blue on CoO/TUD-1 Catalyst}

Methylene blue (MB) is a cationic thiazine dye, which contains condensed rings with sulphur heteroatoms [49]. The chromophoric absorptions $\left(\lambda_{\max }\right)$ of the MB dye were observed at $665 \mathrm{~nm}$ and $291 \mathrm{~nm}$ in the UV-visible spectrum (Figure 8). The effect of the oxidant concentration on the reaction at different time intervals is illustrated in Figure $8 \mathrm{~b}$. Within a short time (below $30 \mathrm{~min}$ ), the MB degradation began, owing to the degradation of 
the MB compound with hydroxyl radicals $\left({ }^{\circ} \mathrm{OH}\right)$, which were produced on the Co surface. As the reaction time increased, the reduction of $\mathrm{MB}$ also increased linearly for all the three peroxide concentrations. The calculated rate constant suggested that the increase in the $\mathrm{H}_{2} \mathrm{O}_{2}$ concentration increased the rate of reaction significantly. The observed rate constants were $0.003,0.014$ and $0.019 \mathrm{~min}^{-1}$, respectively, for the different concentrations of (2.6, 6.4 and $12.8 \mathrm{mmol} / \mathrm{L}$ ) $\mathrm{H}_{2} \mathrm{O}_{2}$. At $240 \mathrm{~min}$, approximately $95 \%$ of the $\mathrm{MB}$ molecules were degraded, which was inferred from the disappearance of the chromophore absorption intensities for $12.8 \mathrm{mmol} / \mathrm{L}$. Hence, the addition of $12.8 \mathrm{mmol} / \mathrm{L}$ of $\mathrm{H}_{2} \mathrm{O}_{2}$ was sufficient for the stoichiometric production of hydroxyl radicals on the CoO/TUD-1 catalyst for the degradation of the MB dye. These optimum conditions were chosen for further studies.
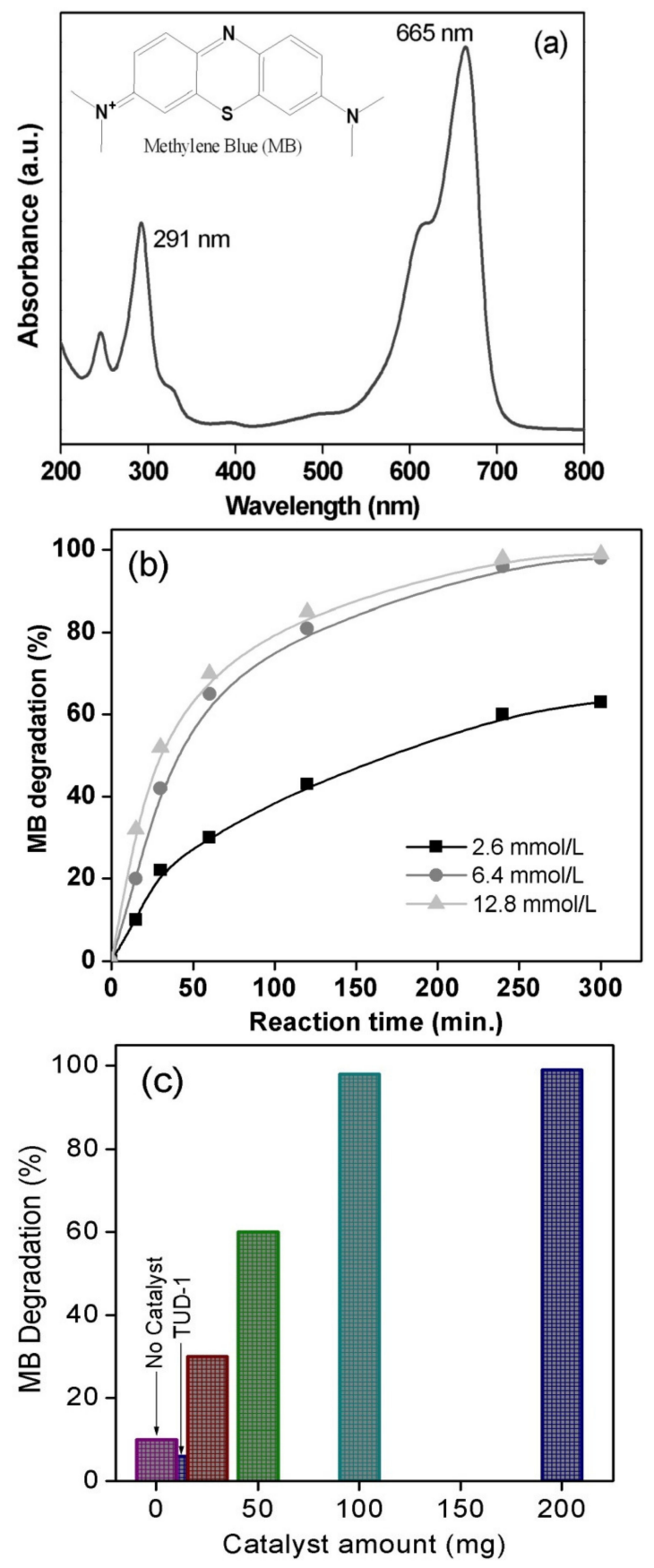

Figure 8. (a) UV-visible spectrum of MB. (b) Influence of $\mathrm{H}_{2} \mathrm{O}_{2}$ oxidant concentration on $\mathrm{MB}$ degradation at different time intervals. (c) Influence of catalyst dose on $\mathrm{MB}$ degradation (Reaction

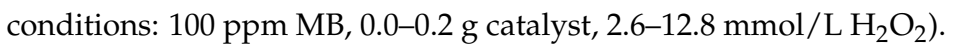


Figure $8 \mathrm{c}$ depicts the degradation of the $\mathrm{MB}$ dye in the presence of the $\mathrm{CoO} / \mathrm{TUD}-1$ catalyst with $12.8 \mathrm{mmol} / \mathrm{L}$ of $\mathrm{H}_{2} \mathrm{O}_{2}$. When the reaction proceeded, a low amount of catalyst (below $50 \mathrm{mg}$ ) was noticed below $60 \%$ degradation activity. This could be explained by the fact that the addition of the catalyst could only increase the available active sites for the synergistic adsorption and catalytic degradation of $\mathrm{MB}$, and thus the low amount of catalyst might have generated a lower amount of radicals. The catalytic dose of $0.1 \mathrm{~g} / \mathrm{L}$ and $0.2 \mathrm{~g} / \mathrm{L}$ revealed a significant increase in degradation ability ( $95 \%)$, which signified that effective radical generation was directly proportional to the available active sites for the reaction mixture. Further, a $0.1 \mathrm{~g} / \mathrm{L}$ dose of catalyst was itself sufficient to achieve $95 \%$ degradation of the MB. Hence, the optimum catalyst dose was $0.1 \mathrm{~g} / \mathrm{L}$ for the degradation of $100 \mathrm{ppm}$ $\mathrm{MB}$ solution. Interestingly, in the absence of the $\mathrm{CoO} / \mathrm{TUD}-1$ catalyst i.e., a homogeneous oxidation process, only $10 \% \mathrm{MB}$ degradation was achieved. This clearly confirms that the presence of the CoO/TUD-1 catalyst significantly enhanced the radical formation potential and was thus responsible for the MB degradation. This result clearly indicates the importance of the Co catalyst for the generation of hydroxyl $\left({ }^{\circ} \mathrm{OH}\right)$ and peroxyl $\left({ }^{\circ} \mathrm{OOH}\right)$ radicals $[28,29]$. Similar Fenton-type radical-generated molecular degradations are reported for CuTUD-1 and FeTUD-1 catalysts.

\section{Conclusions}

In summary, cobalt-loaded TUD-1 prepared by the hydrothermal method exhibited an amorphous, three-dimensional, disordered structure, with cobalt dispersed in the mesoporous channels. In the FT-IR analysis, the asymmetrical and symmetrical stretching vibrations of the $\mathrm{Si}-\mathrm{O}-\mathrm{Si}$ bond present in the TUD-1 were confirmed by the intense vibration bands detected at 1238, 1087 and $804 \mathrm{~cm}^{-1}$. The resulting materials exhibited a surface area of $420 \mathrm{~m}^{2} / \mathrm{g}$, a pore size of $6.8 \mathrm{~nm}$ and an octahedrally coordinated $\mathrm{Co}^{3+}$ species. The DFT studies further confirmed the occurrence of electron transfers from the cobalt to the TUD-1 during the degradation reaction. Furthermore, the calculated adsorption energy clearly established the fact that the parallel absorption configuration on the Co/TUD-1 provided better adsorption and degradation of MB. The optimum time, the $\mathrm{H}_{2} \mathrm{O}_{2}$ and the catalyst amount required for the degradation were found to be $240 \mathrm{~min}, 12.8 \mathrm{mmol} / \mathrm{L}$ and $0.1 \mathrm{~g} / \mathrm{L}$, respectively. In the case of the CoO/TUD-1, dispersed, accessible $\mathrm{Co}^{2+}$ and $\mathrm{Co}^{3+}$ species were present on the TUD-1's surface; three-dimensional porous structures and MB molecular orientation near to the active sites helped to degrade $90 \%$ of the dye molecules. Thus, $\mathrm{CoO} / \mathrm{TUD}-1$ can be utilized as a promising material for the removal of organic pollutants present in wastewater.

Supplementary Materials: The following are available online at https:/ /www.mdpi.com/article/10 .3390/sym13091754/s1, Figure S1: Different adsorption configuration of Co@am-SiO 2 .

Author Contributions: Conceptualization, M.P.P.; Data curation, S.B. (Sambath Baskaran); Formal analysis, C.M.; Investigation, S.C.K.; Methodology, R.B.; Supervision, S.B. (Stefano Bellucci). All authors have read and agreed to the published version of the manuscript.

Funding: This research received no external funding.

Institutional Review Board Statement: Not applicable.

Informed Consent Statement: Not applicable.

Data Availability Statement: Not applicable.

Acknowledgments: The author M.P.P is thankful to R. Anand and R. Maheswari, Center for Environmentally Beneficial Catalysis (CEBC), The University of Kansas, USA for their research supports and guidance.

Conflicts of Interest: The authors declare no conflict of interest. The funders had no role in the design of the study; in the collection, analyses, or interpretation of data; in the writing of the manuscript; or in the decision to publish the results. 


\section{Acronym and Abbreviations}

$\begin{array}{ll}\text { TUD-1 } & \text { Technische Universiteit Delft } \\ \text { DFT } & \text { Density Functional Theory } \\ \text { MB } & \text { methylene blue } \\ \text { TEOS } & \text { Tetraethyl orthosilicate } \\ \text { TEA } & \text { Triethanolamine } \\ \text { TEAOH } & \text { Tetraethyl ammonium hydroxide } \\ \text { VASP } & \text { Vienna ab initio simulation package } \\ \text { PAW } & \text { Projector augmented wave } \\ \text { PBE } & \text { Perdew-Burke-Ernzerhof } \\ \text { EDD } & \text { Electron density differences } \\ \text { EF } & \text { Fermi level } \\ E_{a d} & \text { adsorption energy }\end{array}$

\section{References}

1. Khan, S.T.; Malik, A. Engineered nanomaterials for water decontamination and purification: From lab to products. J. Hazard. Mater. 2019, 363, 295-308. [CrossRef]

2. Crini, G.; Lichtfouse, E. Advantages and disadvantages of techniques used for wastewater treatment, Environ. Chem. Lett. 2019, 17, 145-155. [CrossRef]

3. Bolisetty, S.; Peydayesh, M.; Mezzenga, R. Sustainable technologies for water purification from heavy metals: Review and analysis. Chem. Soc. Rev. 2019, 48, 463-487. [CrossRef]

4. Rafatullah, M.; Sulaiman, O.; Hashim, R.; Ahmad, A. Adsorption of methylene blue on low-cost adsorbents: A review. J. Hazard. Mater. 2010, 177, 70-80. [CrossRef] [PubMed]

5. Sangpour, P.; Hashemi, F.; Moshfegh, A.Z. Photoenhanced degradation of methylene blue on cosputtered $\mathrm{M}: \mathrm{TiO} 2(\mathrm{M}=\mathrm{Au}, \mathrm{Ag}$ $\mathrm{Cu}$ ) nanocomposite systems: A comparative study. J. Phys. Chem. C 2010, 114, 13955-13961. [CrossRef]

6. Wu, Q.; Zhang, H.; Zhou, L.; Bao, C.; Zhu, H.; Zhang, Y. Synthesis and application of rGO/CoFe $\mathrm{O}_{2}$ composite for catalytic degradation of methylene blue on heterogeneous Fenton-like oxidation. J. Taiwan Inst. Chem. Eng. 2016, 67, 484-494. [CrossRef]

7. Houas, A.; Lachheb, H.; Ksibi, M.; Elaloui, E.; Guillard, C.; Herrmann, J.M. Photocatalytic degradation pathway of methylene blue in water. Appl. Catal. B Environ. 2001, 31, 145-157. [CrossRef]

8. Ong, S.A.; Toorisaka, E.; Hirata, M.; Hano, T. Biodegradation of redox dye Methylene Blue by up-flow anaerobic sludge blanket reactor. J. Hazard. Mater. 2005, 124, 88-94. [CrossRef]

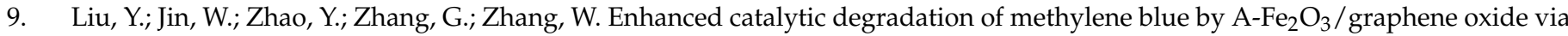
heterogeneous photo-Fenton reactions. Appl. Catal. B Environ. 2017, 206, 642-652. [CrossRef]

10. Cheng, S.; Oatley, D.L.; Williams, P.M.; Wright, C.J. Characterisation and application of a novel positively charged nanofiltration membrane for the treatment of textile industry wastewaters. Water Res. 2012, 46, 33-42. [CrossRef]

11. Kim, S.; Yu, M.; Yoon, Y. Fouling and Retention Mechanisms of Selected Cationic and Anionic Dyes in a Ti ${ }_{3} \mathrm{C}_{2} \mathrm{Tx} \mathrm{MXene}^{-}$ Ultrafiltration Hybrid System. ACS Appl. Mater. Interfaces 2020, 12, 16557-16565. [CrossRef]

12. Mudliar, R.; Umare, S.S.; Ramteke, D.S.; Wate, S.R. Energy efficient-Advanced oxidation process for treatment of cyanide containing automobile industry wastewater. J. Hazard. Mater. 2009, 164, 1474-1479. [CrossRef]

13. Mandal, T.; Maity, S.; Dasgupta, D.; Datta, S. Advanced oxidation process and biotreatment: Their roles in combined industrial wastewater treatment. Desalination 2010, 250, 87-94. [CrossRef]

14. Nidheesh, P.V.; Gandhimathi, R.; Ramesh, S.T. Degradation of dyes from aqueous solution by Fenton processes: A review. Environ. Sci. Pollut. Res. 2013, 20, 2099-2132. [CrossRef]

15. Wang, Q.; Tian, S.; Ning, P. Ferrocene-catalyzed heterogeneous fenton-like degradation of methylene blue: Influence of initial solution pH. Ind. Eng. Chem. Res. 2014, 53, 6334-6340. [CrossRef]

16. Jia, Z.; Kang, J.; Zhang, W.C.; Wang, W.M.; Yang, C.; Sun, H.; Habibi, D.; Zhang, L.C. Surface aging behaviour of Fe-based amorphous alloys as catalysts during heterogeneous photo Fenton-like process for water treatment. Appl. Catal. B Environ. 2017, 204, 537-547. [CrossRef]

17. Wang, Q.; Chen, M.; Lin, P.; Cui, Z.; Chu, C.; Shen, B. Investigation of FePC amorphous alloys with self-renewing behaviour for highly efficient decolorization of methylene blue. J. Mater. Chem. A 2018, 6, 10686-10699. [CrossRef]

18. Liang, S.X.; Wang, X.; Zhang, W.; Liu, Y.; Wang, W.; Zhang, L.C. Selective laser melting manufactured porous Fe-based metallic glass matrix composite with remarkable catalytic activity and reusability. Appl. Mater. Today 2020, 19, 100543. [CrossRef]

19. Liang, S.X.; Jia, Z.; Liu, Y.; Zhang, W.; Wang, W.; Lu, J.; Zhang, L.C. Metallic Glasses: Compelling Rejuvenated Catalytic Performance in Metallic Glasses. Adv. Mater. 2018, 30, 1-11. [CrossRef]

20. Kirchon, A.; Zhang, P.; Li, J.; Joseph, E.A.; Chen, W.; Zhou, H.C. Effect of Isomorphic Metal Substitution on the Fenton and Photo-Fenton Degradation of Methylene Blue Using Fe-Based Metal-Organic Frameworks. ACS Appl. Mater. Interfaces 2020, 12, 9292-9299. [CrossRef] [PubMed] 
21. Dou, R.; Cheng, H.; Ma, J.; Qin, Y.; Kong, Y.; Komarneni, S. Catalytic degradation of methylene blue through activation of bisulfite with CoO nanoparticles. Sep. Purif. Technol. 2020, 239, 116561. [CrossRef]

22. Bibi, I.; Nazar, N.; Iqbal, M.; Kamal, S.; Nawaz, H.; Nouren, S. Green and eco-friendly synthesis of cobalt-oxide nanoparticle: Characterization and photo-catalytic activity. Adv. Powder Technol. 2017, 28, 2035-2043. [CrossRef]

23. Hu, P.; Long, M.; Environ, A.C.B. Cobalt-catalyzed sulfate radical-based advanced oxidation: A review on heterogeneous catalysts and applications. Appl. Catal. B Environ. 2016, 181, 103-117. [CrossRef]

24. Shukla, P.R.; Wang, S.; Sun, H.; Ang, H.M.; Tadé, M. Activated carbon supported cobalt catalysts for advanced oxidation of organic contaminants in aqueous solution. Appl. Catal. B Environ. 2010, 100, 529-534. [CrossRef]

25. Stoyanova, M.; Slavova, I.; Christoskova, S.; Ivanova, V. Catalytic performance of supported nanosized cobalt and iron-cobalt mixed oxides on $\mathrm{MgO}$ in oxidative degradation of Acid Orange 7 azo dye with peroxymonosulfate. Appl. Catal. A Gen. 2014, 476, 121-132. [CrossRef]

26. Hamdy, M.S.; Ramanathan, A.; Maschmeyer, T. Co-TUD-1: A Ketone-Selective Catalyst for Cyclohexane Oxidation. Chem. Eur. J. 2006, 1782-1789. [CrossRef]

27. Hamdy, M.S.; Mul, G.; Wei, W.; Anand, R.; Hanefeld, U. Fe, Co and Cu-incorporated TUD-1: Synthesis, characterization and catalytic performance in $\mathrm{N}_{2} \mathrm{O}$ decomposition and cyclohexane oxidation. Catal. Today 2005, 110, 264-271. [CrossRef]

28. Pachamuthu, M.P.; Karthikeyan, S.; Maheswari, R.; Lee, A.F.; Ramanathan, A. Fenton-like degradation of Bisphenol A catalyzed by mesoporous Cu/TUD-1. Appl. Surf. Sci. 2017, 393, 67-73. [CrossRef]

29. Pachamuthu, M.P.; Rajalakshmi, R. RSC Advances Direct glycol assisted synthesis of an amorphous mesoporous silicate with framework incorporated $\mathrm{Co}^{2+}$ : Characterization and catalytic application in ethylbenzene oxidation. RSC Adv. 2014, 4, 2990929916. [CrossRef]

30. Kresse, G.; Furthmüller, J. Efficiency of ab-initio total energy calculations for metals and semiconductors using a plane-wave basis set. Comput. Mater. Sci. 1996, 6, 15-50. [CrossRef]

31. Kresse, G.; Hafner, J. Ab initio molecular dynamics for liquid metals. Phys. Rev. B 1993, 47, 558-561. [CrossRef] [PubMed]

32. Kresse, G.; Hafner, J. Ab initio molecular-dynamics simulation of the liquid-metal-amorphous-semiconductor transition in germanium. Phys. Rev. B 1994, 49, 14251-14269. [CrossRef]

33. Blöchl, P.E. Projector augmented-wave method. Phys. Rev. B 1994, 50, 17953-17979. [CrossRef]

34. Perdew, J.P.; Burke, K.; Ernzerhof, M. Generalized Gradient Approximation Made Simple. Phys. Rev. Lett. 1996, 77, 3865-3868. [CrossRef] [PubMed]

35. Grimme, S. Semiempirical GGA-type density functional constructed with a long-range dispersion correction. J. Comput. Chem. 2006, 27, 1787-1799. [CrossRef]

36. Tang, W.; Sanville, E.; Henkelman, G. A grid-based Bader analysis algorithm without lattice bias. J. Phys. Condens. Matter. 2009, 21, 1-7. [CrossRef] [PubMed]

37. Yu, M.; Trinkle, D.R. Accurate and efficient algorithm for Bader charge integration. J. Chem. Phys. 2011, 134, 1-8. [CrossRef] [PubMed]

38. Liang, S.X.; Jia, Z.; Zhang, W.C.; Li, X.F.; Wang, W.M.; Lin, H.C.; Zhang, L.C. Ultrafast activation efficiency of three peroxides by Fe78Si9B13 metallic glass under photo-enhanced catalytic oxidation: A comparative study. Appl. Catal. B Environ. 2018, 221, 108-118. [CrossRef]

39. Miao, F.; Wang, Q.; Di, S.; Yun, L.; Zhou, J.; Shen, B. Enhanced dye degradation capability and reusability of Fe-based amorphous ribbons by surface activation. J Material Sci. Tech. 2020, 53, 163-173. [CrossRef]

40. Anand, R.; Hamdy, M.S.; Hanefeld, U.; Maschmeyer, T. Liquid-phase oxidation of cyclohexane over Co-TUD-1. Catal. Lett. 2006, 95, 113-117. [CrossRef]

41. Pachamuthu, M.P.; Shanthi, K.; Luque, R.; Ramanathan, A. SnTUD-1: A Solid Acid Catalyst for Three Component coupling reactions at room temperature. Green Chem. 2013, 15, 2158-2166. [CrossRef]

42. Islam, M.M.; Costa, D.; Calatayud, M.; Tielens, F. Characterization of Supported Vanadium Oxide Species on Silica: A Periodic DFT Investigation. J. Phys. Chem. C. 2009, 113, 10740-10746. [CrossRef]

43. Wojtaszek, A.; Sobczak, I.; Ziolek, M.; Tielens, F. Gold Grafted to Mesoporous Silica Surfaces, a Molecular Picture. J. Phys. Chem. C 2009, 113, 13855-13859. [CrossRef]

44. Tranca, D.C.; Wojtaszek-Gurdak, A.; Ziolek, M.; Tielens, F. Supported and inserted monomeric niobium oxide species on/in silica: A molecular picture. Phys. Chem. Chem. Phys. 2015, 17, 22402-22411. [CrossRef] [PubMed]

45. Siodla, T.; Sobczak, I.; Ziolek, M.; Tielens, F. Theoretical and experimental insight into zinc loading on mesoporous silica. Microporous Mesoporous Mater. 2018, 256, 199-205. [CrossRef]

46. Handzlik, J.; Grybos, R.; Tielens, F. Structure of Monomeric Chromium(VI) Oxide Species Supported on Silica: Periodic and Cluster DFT Studies. J. Phys. Chem. C 2013, 117, 8138-8149. [CrossRef]

47. Vankimmenade, E.; Kuiper, A.; Tamminga, Y.; Thune, P.; Niemantsverdriet, J. A surface science model for the Phillips ethylene polymerization catalyst: Thermal activation and polymerization activity. J. Catal. 2004, 223, 134-141. [CrossRef]

48. Hu, B.; Schweitzer, N.M.; Das, U.; Kim, H.; Niklas, J.; Poluektov, O.; Curtiss, L.A.; Stair, P.C.; Miller, J.T.; Hock, A.S.; et al. Selective propane dehydrogenation with single-site Coll on $\mathrm{SiO}_{2}$ by a non-redox mechanism. J. Catal. 2015, 322, 24-37. [CrossRef]

49. Vandarkuzhali, S.A.A.; Karthikeyan, S.; Viswanathan, B.; Pachamuthu, M.P. Arachis hypogaea derived activated carbon/Pt catalyst: Reduction of organic dyes. Surf. Interfaces 2018, 13, 101-111. [CrossRef] 